\title{
Behavioral Ecology and Sociobiology at 40
}

\author{
Theo C. M. Bakker ${ }^{1}$ James F. A. Traniello ${ }^{2}$
}

Published online: 29 October 2016

(C) Springer-Verlag Berlin Heidelberg 2016

Behavioral Ecology and Sociobiology (BES) turns 40 this year, and there is much to celebrate. Founded in 1976 by Hubert (Jim) Markl, Professor of Biology at the University of Konstanz, Germany, at that time, BES has long been a distinguished venue for the publication of original research and reviews in behavioral science. BES made its appearance when the then-nascent disciplines that focus on the adaptive nature of behavior and social organization, pioneered in the seminal works of Wilson (1975), Dawkins (1976), and Krebs and Davies (1976), began to take wing. Jim Markl, who died in 2015 (see obituary by Hölldobler 2015), was the Managing Editor of the new journal, and John Crook (deceased in 2011), Bert Hölldobler, Hans Kummer, and Edward O. Wilson were co-editors - all preeminent authorities in their fields then and to this day. Karl von Frisch, Nobel Laureate (1973), contributed the foreword for the first issue, rhetorically musing on the fate of the journal, expressing the concerns of a new parent ("Will the new infant flourish?"), but confidently predicting its success ("We do not have to worry about the future of the new child .... the editorial responsibility lies in the best hands"). A review of the inaugural issue by James Gould (1977) forecasted that BES "should become the central journal for the synthesis of ethology, ecology and evolution" as it has "the best people in the field as editors." Indeed, according to impact factor, $B E S$ ranks among the top journals devoted to behavioral biology (Bakker and Traniello 2011). Since 1976,

Theo C. M. Bakker

tbakker@evolution.uni-bonn.de

1 Institute for Evolutionary Biology and Ecology, University of Bonn, An der Immenburg 1, 53121 Bonn, Germany

2 Department of Biology, Boston University, 5 Cummington Mall, Boston, MA 02215, USA
$B E S$ has published a total of 5096 articles that have been cited 186,455 times, achieving a 5-year impact factor of 2.778 and an $h$ index of 139 (ISI Journal Citation Reports).

The first issue of BES appeared in March 1976 and contained four articles, three of which were on social insects. Exactly 40 years later, the March 2016 issue of BES, as a representative sample of recent issues, contains 14 articles, four of which concern social insects, illustrating the enhanced breadth of the journal through an increasing diversity of study taxa and expansion of conceptual approaches and technological capabilities (Fig. 1). An examination of the focal species of articles published in BES during 1976 and 1977 (4 issues/ year, a total of 48 articles) with those in 2015 (12 issues, a total of 190 articles) suggests that the use of social insect models in the early years of $B E S$, likely fueled by the prolific research of co-editors Wilson and Hölldobler as well as the path-breaking work on altruism of Hamilton (1964), Trivers (1971), and Trivers and Hare (1976), provided an impetus for the expansion of research that today marks $B E S$. Social insects remain current and significant model systems (e.g., Robson and Traniello 2016). As the fields of behavioral ecology and sociobiology grew and diversified (see below), studies on birds became more frequent (Fig. 1), perhaps due to the great variability in avian behavioral systems and their suitability as models. Mammalian systems are important as well (Fig. 1), and researchers in this area have steadily and significantly advanced behavioral biology through their contributions to $B E S$.

The Editorial Board of $B E S$ expanded from five members in 1976 to 66 in 2016 in order to be able to continue to expertly and efficiently evaluate the diverse and numerous manuscripts submitted. Today, submissions concerning each major taxonomic group and/or conceptual area are skillfully evaluated by renowned authorities. An analysis of the broad study areas of behavioral ecology, similar to that applied by 


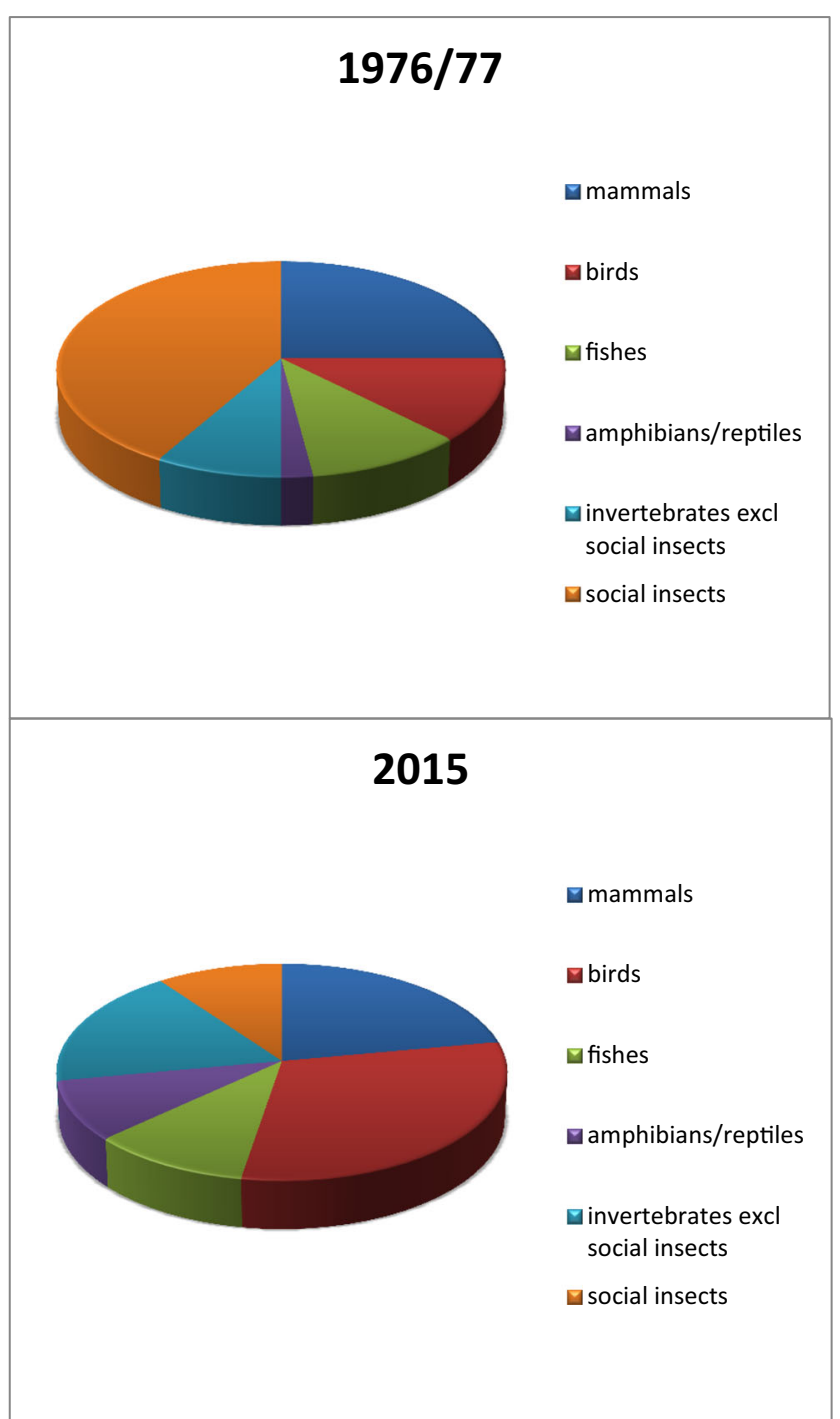

Fig. 1 Representation of taxa in articles published in BES during 1976/ $1977(n=48)$ and in $2015(N=190)$

Simmons (2014) for the journal Behavioral Ecology, showed that sexual selection has been dominant for 40 years in $B E S$, as it has been for the 25 years that Behavioral Ecology has been published. Papers in the categories "sexual selection" and "signaling," which largely concern sexual signals, are frequent (Fig. 2). Within sexual selection research, the study of signaling systems received relatively more attention in the early $B E S$ years, whereas the processes of sexual selection appear en vogue nowadays, relatively speaking. Studies concerning the behavioral ecology of foraging are less frequent, but parental care, predator-prey relationships (including host-parasite interactions), and life history traits (including, in part, animal personality) have gained interest. Studies on social behavior (including but not exclusively covering the conflict and cooperation category of Simmons [2014]) have declined (Fig. 2).

Editors and publishers have the responsibility to serve science and the scientific community by developing and

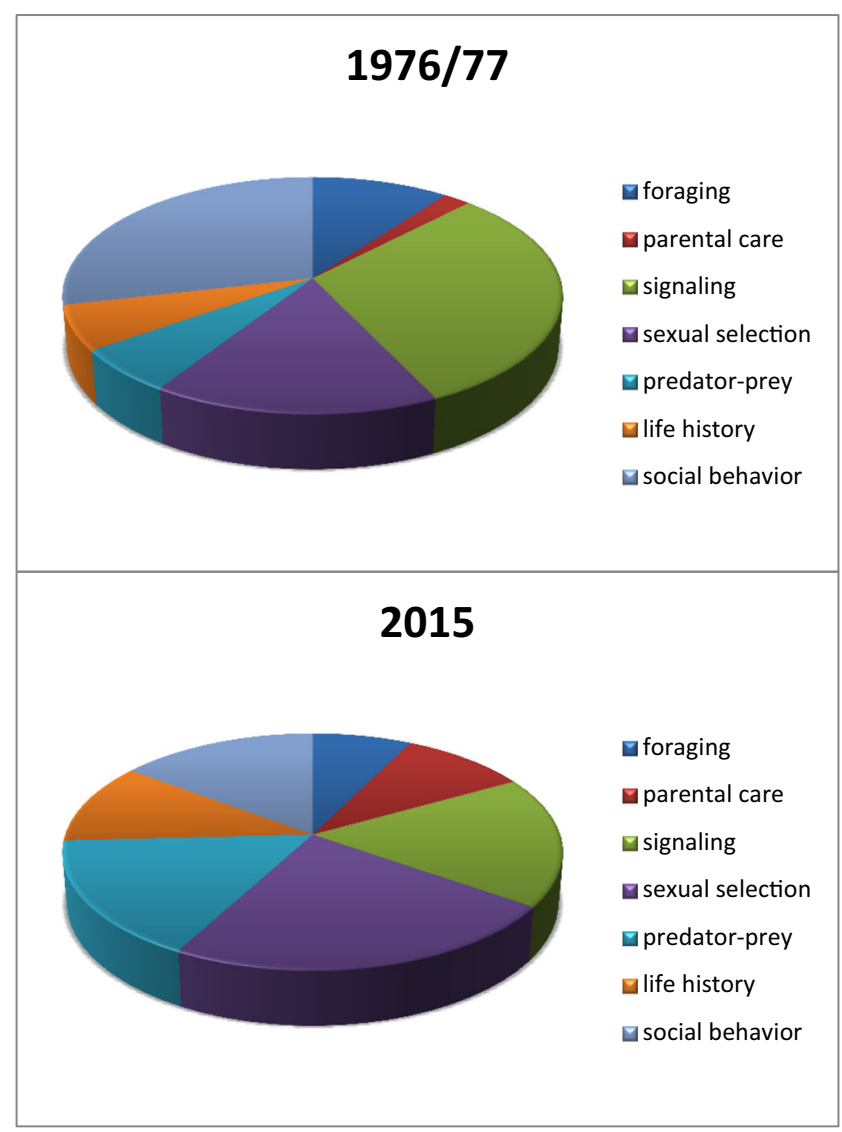

Fig. 2 Representation of articles published in BES during 1976/1977 $(n=49)$ and in $2015(N=190)$ according to broad subject area

implementing best practices to validate research results, make results accessible with minimal delay, and provide guidance to authors to thus ensure published work will be of the highest quality. To these ends, the Editors-in-Chief of BES and Springer continually strive to improve the publishing practices of BES. In October 2015, we introduced the requirement to report the use of blinded methods (Traniello and Bakker 2015). Also in 2015, Springer refrained from charging for color images in print issues. In 2016, we initiated a new section on Featured Student Research Papers dedicated to exceptional, original publications resulting from graduate or undergraduate student research. We have commented on journal selection for article submission (Traniello and Bakker 2013) and cautioned authors about plagiarism (Traniello and Bakker 2016). Beginning in January 2017, Continuous Article Publishing will be practiced: the online-first queue will no longer appear and articles can be appropriately cited as soon as they appear online. Topical Issues will be created to unify articles covering particular themes, and retrospective Virtual Issues of topical papers published in $B E S$ will be produced. The first, on "Division of Labor" by Simon Robson and James Traniello, accompanied their special issue on "Integrative analysis of division of labor" (Robson and Traniello 2016). 
In the post-genomic age, genetic, transcriptomic, and proteomic studies may become increasingly integrated with behavioral ecology and sociobiology ("To me, genomics and behavioral ecology appear to be two parallel worlds with little connection" although "There are rare bridges between the genomic and the phenotypic worlds ... [that] can sometimes be goldmines if we can make use of them." [Milinski 2014]). The delayed integration may be due in part to the complexity of the genetics and plasticity of behavioral traits (Wilkinson et al. 2015). As selection operates on phenotypes, we feel that behavioral ecology will remain phenotype oriented and generate hypotheses for scientists working on genetics or other regulatory mechanisms. Although $B E S$ might not appear to be the most suitable outlet for such studies, a focus on molecular mechanisms underscoring the adaptive nature of behavior may render such papers appropriate. Behavioral ecology and sociobiology are also increasingly bridged to neuroscience, conservation biology, and global climate change, and we welcome contributions representing these interfaces. We anticipate that $B E S$ will continue to serve the prominent role it has had for the past four decades and advance the field in the 40 years to come.

\section{References}

Bakker TCM, Traniello JFA (2011) Editorial: new chief editors. Behav Ecol Sociobiol 65:1669-1670
Dawkins R (1976) The selfish gene. Oxford University Press, Oxford

Gould JL (1977) Behavioral ecology and sociobiology. Volume 1, Number 1, 1976. Q Rev Biol 52:435

Hamilton WD (1964) The genetical evolution of social behaviour I \& II. J Theor Biol 7:1-52

Hölldobler B (2015) Obituary: Hubert (Jim) Markl 1938-2015. Behav Ecol Sociobiol 69:519-521

Krebs JR, Davies NB (eds) (1976) Behavioural ecology: an evolutionary approach, 1st edn. Blackwell, Oxford

Milinski M (2014) The past and the future of behavioral ecology. Behav Ecol 25:680-684

Robson SKA, Traniello JFA (eds) (2016) Integrative analysis of division of labor. Behav Ecol Sociobiol 70:995-1115

Simmons LW (2014) Editorial: 25 years of Behavioral Ecology. Behav Ecol 25:1-3

Traniello JFA, Bakker TCM (2013) Editorial fairness: speed, accuracy and awareness benefit authors. Trends Ecol Evol 29:68-69

Traniello JFA, Bakker TCM (2015) Editorial: minimizing observer bias in behavioral research: blinded methods reporting requirements for Behavioral Ecology and Sociobiology. Behav Ecol Sociobiol 69: 1573-1574

Traniello JFA, Bakker TCM (2016) Editorial: intellectual theft: the pitfalls and consequences of plagiarism. Behav Ecol Sociobiol 70:1789 1791

Trivers RL (1971) The evolution of reciprocal altruism. Q Rev Biol 46: $35-57$

Trivers RL, Hare H (1976) Haplodiploidy and the evolution of the social insect. Science 191:249-263

Wilkinson GS, Breden F, Mank JE et al (2015) The locus of sexual selection: moving sexual selection studies into the post-genomics era. J Evol Biol 28:739-755

Wilson EO (1975) Sociobiology: the new synthesis. Harvard University Press, Cambridge 